\title{
Cultural Transmission in the ELT Classroom
}

\author{
Ming-Ming Che \\ Xi'an University of Technology, Xi'an, Shaanxi, P. R. China \\ E-mail: xutcmm@163.com
}

\begin{abstract}
Although an integral part of language, culture, a necessary dimension of teaching, has been largely ignored in the ELT profession in China. This paper firstly expounds the omnipresent cultural elements involved in the ELT classrooms, and then it points to the assertion that cultural transmission should be regarded as a dynamic part of ELT in China. The ultimate objective of the paper is to draw the attention of the ELT teachers to the cultural facets of language and to urge them to change their teaching approach accordingly.
\end{abstract}

Keywords-culture; cultural transmission; cultural differences; cultural awareness

\section{INTRODUCTION}

Culture is pervasive and it permeates in every aspect of our daily life. The impact of culture on language is so tremendous that scarcely any language phenomenon can be understood without careful consideration of its cultural background. Needless to say, culture should also be a constituent part of language teaching.

The importance of culture as a part of language teaching has been realized, "If ... language is seen as social practice, culture becomes the very core of language teaching. Cultural awareness must ... be viewed both as enabling language proficiency and as being the outcome of reflection on language proficiency"[1]. To a degree, for the students who aim to master a foreign language, cultural acquisition is a must. Teachers should realize that making use of the cultural elements and implications both inside and outside the classroom may greatly facilitate the students' learning of the English language.

Thus, it is high time that we language teachers developed a cultural perspective and viewed culture as an integral part which helps information and knowledge to be more efficiently relayed. As the world has evolved into the global village, an equally important issue for us is to cultivate students' cultural awareness and cultural sensitivity so that they can communicate effectively with people of other cultures.

The characteristics of culture manifest themselves in a host of ways, and the following aspects are what a teacher is supposed to pay heed to in his transmitting of knowledge or his cultural input in the ELT classroom.

\section{CULTURAL DIFFERENCES IN THE ELT CLASSROOM}

\section{A. Nonverbal Behaviors}

For his smooth communication and good performance both in college or in the future, one important aspect of things that a foreign language student should acquire are nonverbal behaviors. Nonverbal behaviors are related to culture and they form a powerful system of communication. They take on a variety of forms and generally include gestures, facial expressions, and eye movements, etc. A Chinese student comes from a cultural background which has its well-established norms as to typical and acceptable behaviors. Were he to have an American teacher, he would feel at a loss what to expect from the teacher and what behaviors the teacher expects of him and may even find some of the teacher's behaviors confusing and incomprehensible. Thus, the differences in nonverbal behavior among cultures, if not properly decoded, may cause breakdowns in intercultural communication.

Smile is a nonverbal behavior that is deeply rooted in every culture. Being members of a High-Context Culture (HCC) [2], Americans exchange their ideas in a more direct and more emotional way. Maybe that is why they smile much more than the reserved Chinese people. Suppose an American who is new to a student smiles at him, the student should not feel confused or embarrassed, rather, he should be friendly enough to smile back. He need not abide by the Chinese custom of only smiling at people whom he really knows.

The American attitude toward eye contact stands in contrast with the Chinese one. Looking at the other person in the eye is a way of indicating that someone is trying to communicate with him, or that he is listening to what the person is saying. And enthusiastic eye contact is considered to be attentive and respectful, while lack of it is thought to be rude. In the Chinese culture, however, a thoughtful person does not look directly into the other person's eyes. In so doing, he or she will not prove to be decent. Thus, misunderstanding could occur if the opposing ideas in this regard are not fully recognized or understood.

Due to the natural differentiation of the Chinese culture and the American culture, nonverbal behaviors in the Chinese classroom and the American classroom seem to fall into two distinctive categories. By and large, a Chinese classroom is calm and orderly while an American classroom is characterized by its freedom and leisurely atmosphere. Correspondingly, both Chinese students and teachers and their American counterparts behave differently. Chinese students tend to be quiet and obedient even after they have sat for an extended period of time, whereas American students appear to be noisy or at times even disruptive. If a student is late, he has to knock at the door to make his presence known or report his presence by asking "May I come in?", whereas it seems Okay for an American student 
to break in if he is late. A Chinese teacher, more often than not, impresses the students as being serious, authoritative and businesslike. During his class, he may not hesitate to send a stern expression to any student who is disruptive. An American teacher appears in a way to be warm and unthreatening. He gives a warm greeting at the beginning of each class and bids a warm good-bye at the end of the class as well. So before leaving the classroom, he would talk at length about what the students should do either related or unrelated to the class (Typical farewell addresses are: Be Happy! Keep smiling! Keep practicing English! ...). During his class, the students feel free to voice their opinions and feelings openly and candidly and they may be allowed to interrupt the teacher abruptly if he has an opinion to express. Unlike a Chinese teacher who seriously and respectfully remains on the lecture platform, an American teacher may give a lecture by sitting on the lecture platform.

The list of different nonverbal behaviors could still go on. Truthfully, both inside and outside the classroom, nonverbal behaviors form a major branch of knowledge in communication. Ideally, the student should be familiar with various nonverbal behaviors in order to enhance communication and improve learning as well.

\section{B. Cultural differences in pragmatics}

So far, this paper has left out the most important area in which cultural differences exist, the pragmatic aspect of culture. There are a multitude of practical examples indicating that the Chinese language and the English language are pragmatically different due to their cultural characteristics.

One of the most common pragmatic differences that involve cultural significance lies in the way of thinking. Contrary to the typical western logical thinking, Chinese culture emphasizes the integration of man and earth, and the thinking pattern of the Chinese people is non-logic and holistic. Unlike the English language which expresses the exactness of time, the tense of an uttered message is decided from the context. Chinese people are so accustomed to fuzzy logic and the holistic thinking mode that they are at a loss when it comes to analyzing the specific tense of an event. In addition, Chinese people do not refer to the specific number of something unless it is specifically necessary. For instance, a beginner usually spends a hard time adapting himself to the rule that the word "money" is an uncountable noun, since money is of course "countable" - can be counted to see how much it is! So is the case with "time", which could be counted by the hour, minute and second. And in the case of "fish", "sheep" and "offspring", etc., the student finds it difficult to accept the rule that both their singular and plural forms are the same. Ironically, this is again difficult for the student who has just acquired that little sense of pragmatic usage of the English language. Yet accidentally, lack of the countable and uncountable system in Chinese actually makes the student comply with the rule in this regard!

Another aspect of the English grammar that has a touch of cultural significance is passive voice. Passive voice is prevalent in the English language, and for a language teacher it proves quite effective in formulating the classroom policies. A teacher should not take it for granted that his students would unconditionally accept all the instructions and requirements he sets for them. To guarantee the implementation of the policies and help the classroom run smoothly and efficiently, passive voice, which makes it possible that the rules and teaching procedures are presented in an informational and objective manner, is highly recommendable in establishing a friendly classroom climate.

For example, if a teacher requires that the students submit assignments before a deadline and he will refuse them after the due time, he may express the policy as "Late work won't be accepted" rather than "I accept no late work". In this way, he makes his comment less offensive and thus more acceptable. The use of passive voice gives the students a feeling that it is not the teacher himself who is very picky and forces them to do such and such things, but it is just their obligation to cooperate with the teacher and behave well. Other situations in which the use of passive voice is involved in stating a teacher's requirements for a class may be:

Punctual attendance should be guaranteed.

Good penmanship on all assignments is recommended.

Cheating and plagiarism are not allowed in this classroom.

Small favors such as distributing and collecting the exercise books are highly appreciated.

Not only is passive voice effective in representing an order that seems so authoritative that the students have no choice but to observe, more importantly, it is also the "biological environment" in which the English language naturally exists. As a matter of fact, on a lot more occasions, passive voice is employed to pass on the meaning in the English language than in Chinese. To realize this point is beneficial to a teacher and is vital for the students to grasp the true spirit of the English language as well.

After the so-called period of "cultural shock" in learning English grammar, what the student ought to do is to adapt himself to the linguistic habits of the language. As a matter of fact, there are a lot more of pragmatic cases where culture sense is to be required. For instance, in translation, the subtlety of the culture-loaded elements should be effectively dealt with so that they still make sense in the Chinese language. A case in point is the English proverb: "One swallow does not make a summer." In Chinese, it should be "One swallow does not make a spring." This is perhaps because spring is the time when swallows come to most parts of China. Still another example is the idiom "this is a bread-and-butter issue," meaning the basic issue of life. While in Chinese, the legitimate translation should retain no such elements as "bread and butter", since the basic Chinese livelihood is charcoal, rice, oil and salt. There is yet another example showing that culture plays a more important role than grammar itself in understanding the culture-loaded language phenomenon. The Chinese proverb "Plant onions, and you will get melons; Plant beans, and you will get nothing but beans" is only well accepted if it is rendered 
into English as "When you plant onions, don't expect lilacs to bloom".

These examples indicate that since language, which is the carrier of culture, exists in its own specific linguistic environment, it is thus restricted not only by its own cultural rules but by its pragmatic rules as well. As a result, any one-to-one correspondence of understanding or interpreting may cause divergence or loss of meaning.

\section{AROUSING STUDENTS' CULTURAL AWARENESS}

Thus, to a certain degree, to teach a language is to teach a way of thinking, and even a way of life. This is, however, always easier said than done. On the one hand, grammatical competence has had such a place that among a wealth of pedagogically produced language materials there have been limited materials available which are intended to enhance the students' cultural capabilities. On the other hand, culture is multi-dimensional and helps to increase all language skills and cultural knowledge by offering new insights into social lives, so the teaching of culture is much more demanding than teaching grammatical rules. Nevertheless, however challenging it is, the exploration into culture is supposed to be a compulsory approach to teaching the language well.

Edward Hall categorizes culture as being either a high or low context. A culture in which information and cultural rules are directly and overtly communicated is called a low-context culture (LCC), and the opposite is called a high-context culture (HCC). "American communication is more or less independent of the context in which it takes place, which is called low-context. By contrast, Asian communication is highly contextualized, which is called high-context" [3]. In a low context culture, information is explicitly stated, and the responsibility for meaning falls mainly to the speaker, whose job is to formulate ideas into clear language. Usually, communicators convey their ideas openly and directly and they are expected to share the common knowledge as to how to behave in a common situation. The Chinese culture is on the reverse side of the American culture, that is, high-context communication is typical of the culture. In a high social context, issues would be expected to have lower clarity and specificity and their meaning to be contingent on context. Communication codes, although not clearly laid out or written down, are commonly lived by.

It is an accepted truism that different values render people to perceive the world differently. When a Chinese student aims to communicate with people of other cultures, say, an American, difficulty arises. Being firmly based on Confucianism, Chinese culture emphasizes middle values and a harmonious relationship between the two extremes. So, modesty and conservation are considered to be the most valued traits for one who possesses a refined taste. His deep-rooted values, if not well recognized and altered, will inevitably hinder communication. For instance, he should realize that face-saving at all costs either for himself or for other people's benefits seems pointless in front of an
American who highly values individuality. What's more, he should have a presence of mind that the fact that he tries to behave well in class by being reserved or by leaving the teacher as much time as possible in order that he could show his authority may be understood by an American teacher as being dull or rude. Lastly, he should be aware of the fact that his mottos "Still waters run deep" and "Speech is silver, while silence is gold" are powerless in the face of the open, noisy Americans. Instead, most Americans may interpret being silent as an indicator of boredom or disinterest.

Conversely, different cultures give rise to different values, beliefs, and attitudes. Yet, for geographical reasons, Chinese students who spend the bulk of their time learning English are mainly surrounded by the Chinese culture, so to speak, they are ruthlessly isolated from the English culture. Rarely do they have the opportunities of being accessible to a foreign culture, which of course radically hampers their acquisition of language.

Therefore, it is the teacher's urgent task to create a cultural atmosphere in the ELT classroom so that the students can gain exposure to the English culture to the greatest degree. In the meantime, what the teacher is supposed to bear in mind is that culture is taught, not caught, which means that it is the teacher who should pass on to the students both cultural knowledge and cultural awareness. By cultivating their cultural interest and cultural sense, the students will be expected to become culturally sensitive, which is undoubtedly beneficial to their language learning, since many a text or learning material involves a large bulk of cultural message and is often culture-loaded.

\section{CONCLUSION}

Weather we examine the different cultural values in nonverbal behaviors or the pragmatic differences, the tendency is obvious: cultural elements are abundant in the ELT classroom. It is the cultural perspective of teaching that helps clear up the hazy ideas about how language is fundamentally structured, and it is this perspective that is likely to produce an adept language learner who can have a perception of language both on the cultural scale and on the grammatical scale. Above all, it should be commonly noted and recognized that the acquisition of cultural phenomena and cultural values is directly proportionate to language acquisition, whereas lack of cultural background is inadequate for a learner to fully and sufficiently master the enormous complexity of a language.

As the world has evolved into the global twenty-first century, teachers of ELT should be more and more aware of the puissant influence of culture on language and language teaching. Only in this way will it be possible for the teachers to help the students to learn English well and get their capabilities of communicating with people of other cultures enhanced.

\section{REFERENCES}

[1] C. Kramsch, Context and Culture in Language Teaching, Shanghai: Shanghai Foreign Language \& Education Press, 2001, pp. 8.

[2] E. T. Hall, The Silent Language. New York: Doubleday, 1959, pp. 169. 
[3] E. T. Hall, Beyond Culture. Garden City, NY: Anchor Doubleday,

1977, pp. 14. 